\title{
Improving Sexual Health in U.S. Rural Communities: Reducing the Impact of Stigma
}

\author{
Jo A. Valentine ${ }^{1} \cdot$ Lyana F. Delgado $^{1} \cdot$ Laura T. Haderxhanaj $^{1} \cdot$ Matthew Hogben $^{1}$
}

Accepted: 29 July 2021 / Published online: 26 August 2021

This is a U.S. government work and not under copyright protection in the U.S.; foreign copyright protection may apply 2021

\begin{abstract}
Sexually transmitted infections (STI), including HIV, are among the most reported diseases in the U.S. and represent some of America's most significant health disparities. The growing scarcity of health care services in rural settings limits STI prevention and treatment for rural Americans. Local health departments are the primary source for STI care in rural communities; however, these providers experience two main challenges, also known as a double disparity: (1) inadequate capacity and (2) poor health in rural populations. Moreover, in rural communities the interaction of rural status and key determinants of health increase STI disparities. These key determinants can include structural, behavioral, and interpersonal factors, one of which is stigma. Engaging the expertise and involvement of affected community members in decisions regarding the needs, barriers, and opportunities for better sexual health is an asset and offers a gateway to sustainable, successful, and non-stigmatizing STI prevention programs.
\end{abstract}

Keywords Sexually transmitted infections $\cdot$ Stigma $\cdot$ Rural populations $\cdot$ Community engagement

\section{Resumen}

Las infecciones de transmisión sexual (ITS), incluyendo al VIH, se encuentran entre las enfermedades más diagnosticadas en los Estados Unidos y representan algunas de las disparidades de salud más significativas. La creciente escasez de servicios de atención médica en entornos rurales limita la prevención y el tratamiento de las ITS para los estadounidenses de zonas rurales. Los departamentos locales de salud son las fuentes principales para el cuidado de las ITS en las comunidades rurales, pero estos proveedores confrontan dos desafíos principales, o una doble disparidad: (1) capacidad inadecuada y (2) malas condiciones de salud entre las poblaciones rurales. Además, en las comunidades rurales la interacción entre el estatus rural y determinantes claves de la salud aumentan las disparidades asociadas a las ITS. Estos determinantes clave pueden incluir factores estructurales, de comportamiento y interpersonales, como el estigma. El involucrar la experiencia y la participación de los miembros de la comunidad afectados en las decisiones sobre las necesidades, barreras y oportunidades para una mejor salud sexual es beneficioso y ofrece una puerta de entrada a programas de prevención de ITS sostenibles, exitosos y no estigmatizantes.

Palabras Clave Infecciones de transmisión sexual · Estigma · Poblaciones rurales · Participación comunitaria

\section{Introduction}

Images of rural America often include idealized scenes of farm fields and open skies, of winding roads and natural landscapes. However, concealed by these pristine notions of rural life, profound challenges affect the health and

Jo A. Valentine

jxv2@cdc.gov

1 Division of STD Prevention, NCHHSTP, Centers for Disease Control, 1600 Clifton Road, MS US12-3, Atlanta, GA 30333, USA wellness of rural citizens [1]. As of 2017, one in five Americans, nearly 60 million people, resided in what is typically defined as rural America [2], and for many of them, basic resources, from grocery stores to high speed 
internet connectivity can be hard to come by and expensive [3]. Determinants of health such as poverty, access to health services including drug treatment, racism often manifested in residential segregation, and social stigma as a consequence of community norms and attitudes are associated with poorer health status among rural Americans $[4,5]$.

To characterize rural America as monolithic risks dismissing important differences based on regions of the country, racial and ethnic minority composition, and growing size of immigrant populations. Rural America is no more uniform than urban America and even population thresholds used to differentiate rural areas from urban centers can vary from 2500 up to 50,000 , depending on the definition $[6,7]$. Currently the U.S. Census Bureau designates an area as rural based on population density, but rural America can encompass prospering exurb communities as well as frontier communities. Such distinctions in the definitions of rural America are critical and must be recognized as they relate to and impact health. One recent analysis found that a rural-urban mortality disparity is not only persistent, but large, and increasing when compared to other place-based disparities, ultimately evolving into a high-poverty rural penalty that rivals the effects of education and exceeds the effects of race [8], although race/ethnicity does factor significantly in the health status of rural populations. Minority populations in rural communities frequently face barriers to accessing health care leading to health disparities and health inequity [9].

The growing scarcity of health care services in rural settings impacts Sexually transmitted infection (STI) prevention and treatment for rural Americans [10-12]. In 2019, the opening phase of Ending the HIV epidemic (EHE) also focused on areas in seven states with a disproportionate burden of HIV in rural areas [13]. Local health departments are the primary source for STI care in rural communities [14]. However, these providers experience two main challenges, also known as a double disparity: (1) inadequate capacity and (2) poor health in rural populations [15]. As the country also contends with the COVID-19 pandemic, ensuring the delivery of quality health care in rural American communities continues to be difficult particularly among rural racial/ethnic minority communities [16]; communities where STI disparities persist. Although health departments in rural jurisdictions typically serve fewer people and have lower levels of staffing and funding than local health departments serving urban areas, the populations they serve experience multiple health disparities, including STIs, related to health behaviors, health outcomes, and access to medical care [17]. Simply put, geography matters when it comes to health [18-21].

\section{STI Rates in Rural Settings}

In the United States, STIs are among the most reported diseases and represent some of America's most significant health disparities. In 2018, an estimated 1 in 5 persons had a sexually transmitted infection [22]. There were $1,808,703$ cases of Chlamydia trachomatis infection reported to the CDC in 2019, making it the most common notifiable condition in the United States. Gonorrhea was the second most common notifiable disease, with a total of reported 616,392. Finally, 2019 saw 38,992 reported cases of Primary and secondary (P and $\mathrm{S}$ ). Across all regions of the country and among racial/ethnic groups, the burden of three common bacterial STIs, chlamydia, gonorrhea, and syphilis continues to increase [23]. Moreover, the burden of STIs facilitates the transmission of HIV in these affected populations [24, 25].

Few studies focus on STI rates in nationally representative rural populations, but clearly STIs are not just an urban American problem. Studies that have focused on STI-related behaviors and rates in rural areas have found disproportionally higher rates of behaviors that increase the risk for STIs in some rural populations by age, race/ethnicity, sexual orientation, and geographic location. Further, for negative health outcomes from STIs, such as HPV-associated cancers, rural females and males have significantly higher rates compared to their urban counterparts [26].

\section{Age}

While STI rates are high among adolescents and young adults nationally, rural youth may have different behavioral risk factors for STI acquisition than their urban peers. For example, $39-44 \%$ of sexually active rural youth reported engaging in sexual intercourse before the age of 14 years, half reported inconsistent or no condom use, and one third reported four or more lifetime partners [27, 28]. In rural Minnesota, for example, higher chlamydia rates were associated with inconsistent condom use among 12th grade males [29]. Further, while STI rates among young people have been customarily reported as higher in urban compared to rural communities, there are shifts to no differences between urban and rural settings and even higher rates in some rural youth populations [30].

\section{Race/Ethnicity}

For the purposes of this paper the authors use the race and ethnic categories described in the Office of management and budget's (OMB) Statistical Policy Directive No. 15 [31]. There are disparities in rates of STIs among some racial minority or Hispanic groups when compared with rates 
among Whites. Broader inequities in social and economic conditions for minority communities are reflected in the profound disparities observed in the incidence of STIs by race and Hispanic ethnicity [23, 32].

\section{Sexual Orientation}

Sexual and gender minorities (SGM), including Lesbian, gay, bisexual, and transgender (LGBT) individuals, in rural areas may have an increased risk of attaining STIs, especially among homosexual men or Men who have sex with men (MSM). For example, MSM in rural areas were significantly less likely to have received an STI test [33]. Similarly, young MSM (YMSM) in rural areas were less likely to have been tested for STIs than urban YMSM [34]. Among 190 Hispanic/Latino MSM in rural North Carolina, 21\% reported sex with at least one woman in the past 3 months, $89 \%$ reported multiple male partners in the past 3 months, and 54\% reported inconsistent condom use [35]. For some rural LGBT residents, there is a high prevalence of inconsistent condom use, sexual activity engaged while under the influence of alcohol and/or drugs, and multiple sex partners with challenges for rural LGBT populations related to HIV testing and low levels of HIV knowledge [36].

\section{Geography}

Because rural populations are not homogenous, it is important to identify the areas where STI rates are highest and where outbreaks may occur. One geographic example is the Delta Regional Authority (DR), a federally designated area of 252 counties and parishes located in eight states (Alabama, Arkansas, Illinois, Kentucky, Louisiana, Mississippi Missouri, and Tennessee) along the Mississippi River and the Alabama Black Belt. Compared to the 719 non-DR counties in those eight states, the STI case rates in the DR counties are $75 \%$ higher for chlamydia, $131 \%$ higher for gonorrhea, and $112 \%$ higher for syphilis [37]. As suggested by findings from Barger and her colleagues, there is an unappreciated burden of STIs in rural areas as evidenced by the Delta Regional Authority being an under-resourced area with limited access to care for STIs.

\section{Key Determinants Affecting STI Prevention among Rural Populations}

In rural communities the interaction of rural status and a given key determinant can increase STI disparities. For example, access to quality STI prevention and control services is a critical determinant of sexual health, and there are many determinants of health that also apply. Applicable determinants may include structural factors such as access to care or personal behaviors such as healthcare-seeking and adverse experiences such as childhood abuse and family violence. These determinants also include interpersonal factors, one of which is stigma. Stigma has been defined as an attribute or label that sets a person apart from others, links the labeled person to undesirable characteristics, and represents socially shared knowledge understood even by the targets of the stigma. Stigma is usually experienced in one or both ways: (1) enacted stigma - when people who are considered to be morally, socially, racially, or physically tainted are discriminated against by "normal" persons; and (2) felt stigma - the fear or experience of this type of discrimination [38]. Either scenario can impede a person's willingness to access health care for STI treatment [39]. Moreover, the growth of the digital culture can influence all these determinants, including the effects of stigma, minimizing or maximizing their positive and negative effects [40].

\section{Poverty}

In the United States, being poor, low Socioeconomic status (SES), can carry its own kind of stigma, often exacerbated by race [41]. Arguably one of the most infamous examples of the intersection of race, poverty, and sexually transmitted disease in a rural community is the U.S. Public Health Service Syphilis Study at Tuskegee, Alabama [42]. SES can affect a patient's interaction in the healthcare setting regardless of the medical issue [43]. Being poor can render quality STI treatment unaffordable, or it can mean it is too far away to get to due to the lack of transportation, particularly in rural settings [44]. Although poverty is not typical of rural residents, a higher proportion of U.S. rural populations (16.4\%) met standards for poverty than in urban areas (12.9\%) in 2017 [45]. Rural counties with high poverty rates ( $>15 \%$ of residents at or below the poverty line) had consistently higher mortality rates than low-poverty rural counties and urban counties regardless of poverty rates [46]. Another study using counties as the unit of analysis returned similar findings for infant mortality, with negative effects for poverty and rural residency [47]. The effect from rural residency persisted even controlling for maternal sociodemographic and health factors.

\section{Racism and Ethnocentrism}

Multiple studies suggest that along with income inequality, the stigma associated with race and ethnicity, i.e., racism and ethnocentrism, is a determinant and plays a detrimental role in health, including sexual health [48-52]. Most of the research examining the relationship between discrimination based on race/ethnicity and health outcomes focuses primarily on urban and suburban populations, but some of the same implications are applicable to rural areas. As an example, 
a recent review of Antiretroviral therapy (ART) initiation delays found racial segregation and, to some extent, rural residence, associated with delayed initiation of care and subsequent adherence [53]. The interplay of social segregation and discrimination and health in rural settings is generally complex [54, 55].

Recent trends in U.S. rural communities include depopulation, aging [56], and increasing racial and ethnic diversity, in addition to lower socioeconomic status and ongoing health concerns [57]. Data from the last two decades suggest migration among racial and ethnic populations in the U.S. has reduced segregation overall, but the effects are greater for urban and suburban settings than for rural ones, and it is driven by people under 40 years of age [58].

Although relatively stable in race/ethnicity composition, the proportion of rural populations identifying as Hispanic has increased by roughly $1.5 \%$ to $2.0 \%$ per year in the past decade [45]; and is currently $9 \%$ of the total U.S. rural population [59]. Approximately $14 \%$ of the U.S. population is foreign-born at the present time, exclusive of citizens by birth who were born outside the U.S. (e.g., born in Puerto Rico or born to U.S. citizens abroad) [2]. Immigration into the U.S. is widespread and brings people to all aspects of the domestic economy and culture. Seasonal labor-focused immigration has long been a feature of rural immigration, including through the long-standing practice of agricultural labor temporary arrangements such as the H2-A visa program. Immigrants from all over the world have also settled in rural areas and small towns on a more permanent basis, sometimes working in industries such as poultry processing, but also as proprietors of small businesses such as grocery and hardware stores, and landscaping companies.

Rural residency can interact with immigration and segregation to confer vulnerability [60]. In some circumstances, rural immigrants might be integrated into a workforce, but otherwise socially and even physically segregated, circumstances that can facilitate infectious disease transmission [61]. Perennial stresses around immigration status may even push immigrants to remain segregated from other rural residents.

Hispanic/Latinos in these communities can find themselves lacking community support and culturally competent health care services [62], affecting their connectivity to sexual health care [63]. In one study from Florida, foreignborn Hispanic/Latino men living with HIV in rural districts in the state, especially where Hispanic/Latinos made up $<25 \%$ of the total population, were more likely to have been diagnosed late in their infection [64]. Another study of young adult Hispanic/Latinos in rural Oregon found that the experience of discrimination was associated with medical mistrust [65] and provided further evidence that health care discrimination is prevalent among young-adult Hispanic/ Latinos living in rural areas, particularly the foreign-born
[66]. However, the authors of the Oregon study also surmised that while discrimination separated Hispanic/Latinos from others in new immigrant communities and likely contributed to mistrust of medical providers, a stronger sense of ethnic identity could also serve as a protective coping mechanism. More research is needed to understand and address the impact of race and ethnicity and social determinants of health in the quality of care [67].

\section{High-Risk Substance Use}

Like poverty, high-risk substance use (e.g., opioids) is not characteristic of all rural areas or of all residents in any rural area, but the health problem does persist and with negative consequences for the STI epidemic [68]. In 2017, almost $25 \%$ of the US population over age 12 reported binge-alcohol use in the past month and approximately $11 \%$ reported illicit drug use in the past month [69]. Although substance use is one of the top 10 priorities of Rural Healthy People 2020, accessing substance abuse treatment is challenging in rural regions [70]. A substantial proportion of the opioid epidemic of the past few years has been located in rural settings and this epidemic has been implicated in HIV and hepatitis spread while being correlated with socioeconomic stress [71-73]. Moreover, substance use as a risk factor for negative health outcomes is not confined to an individual's direct use [74]. Studies continue to show the substantial burden of high-risk substance use and its relationship to STIs among rural populations [28], and because high-risk substance use is often seen as a criminal activity the behavior is accompanied by stigma. In addition these highly stigmatized behaviors and experiences are often correlated with violence, including intimate partner and other family trauma such as child abuse and neglect [75]. While issues pertaining to health care confidentiality and availability particular to rural settings can negatively impact the success of interventions for victims of violence or abuse, community-level prevention efforts in these settings have shown positive results [76].

\section{Attitudes and Community Norms Regarding Sexual Health}

Individual attitudes and community norms around sex and sexuality are related to sexual health. Although rural areas are often seen as more socially conservative than other parts of the U.S., it is important to note that this is not a universal truth. Further, the mechanisms through which attitudes and norms form determinants of sexual health are largely the same in rural settings as in urban and suburban ones. One review of barriers to HPV vaccination in rural settings found attitudes about sexual behavior were a barrier to vaccination in some studies along with parental perceptions of whether their daughters were too young (related to stigma attached 
to HPV vaccine); these studies, however, did not typically examine community norms [77].

In rural areas, where social networks can be small and relationships overlap, understanding the potential impact of stigma on sexual health is critical [78]. Overlapping relationships are regular occurrences in health care settings in rural environments [79]. Local health department staff in rural communities often know their patients, not just as patients, but as neighbors and friends, and in some cases even as relatives. Provider attitude and beliefs about what is normative behavior affects the provider-patient relationship in the STI clinical setting and can determine the success or failure of the encounter. In rural settings such relationships can have critical implications for an STI patient's privacy, confidentiality, and health care seeking behavior. A recent study found that bisexual persons living in rural communities appeared to experience greater stress from having to hide the lesbian/ gay aspects of their lives from their heterosexual peers and the heterosexual aspects of their lives from their lesbian/gay peers [80]. The researchers deemed this phenomenon evidence of the pressures of the double closet experience previously described in the literature [81]. Without the protection of anonymity, the impact of stigma is potentially magnified. The fear of being noticed or identified by fellow community members can lead to resistance to STI testing, avoidance of STI symptom disclosure, and erecting barriers to effective partner notification [82-84].

Therefore, the maintenance of privacy and confidentiality becomes even more critical in rural settings, while at the same time privacy and confidentiality may be more difficult to ensure. The typical scarcity of nearby health care sources increases the odds of patient identifiability in small communities. In a qualitative sample of MSM living in rural sections of Oklahoma and Arkansas, respondents noted a lack of medical providers, privacy, and confidentiality and perceived stigma as overlapping barriers to accessing HIV or STI screening and care [85]. Respondents in the study spoke favorably of at-home testing and medical consultation, a paradigm that is gaining significant ground during the COVID-19 pandemic.

Furthermore, studies have found that provider bias is an especially influential contributor to negative health care experiences for persons from racial/ethnic minority groups compared to Whites [86]. For an individual in a rural community, an STI diagnosis can create significant burden. Loss of safety, jobs, housing, and even family and friends are not uncommon outcomes [30]. Being seen in the local STI clinic can not only compromise an individual's social status but may negatively impact that person's livelihood [87].

In general, negative attitudes towards sexual behaviors or orientation, drug use, and even economic status in rural areas can undermine civic support for sexual health services. Several studies have found that rural residents' denial of the presence of STIs in their communities resulted in limited community champions who were willing and able to mitigate the myths and misconceptions regarding STIs and sexual health, thus impeding effective public health planning and implementation for STI prevention and control [44].

\section{Reducing Stigma Associated with STI Prevention in Rural Communities}

Overcoming the impact of negative determinants of sexual health, including stigma, in rural communities can be challenging. The recently published report regarding the prevention of STIs in the United States, from the National Academies of Sciences, Engineering, and Medicine, calls for a national plan that improves sexual health services for priority populations, such as male, female, transgender adolescents, and young adults. The report also focuses on the expansion of STI services to underserved populations, including Black, Hispanic/Latino, and American Indian/Alaska Native populations, and persons who use drugs, or who engage in sex work [88]. To be effective, interventions aimed at reducing STIs need to address the intersectional impact of multiple determinants of health, as well as the convergence of multiple stigmatized identities within the individual or the group. The geographic isolation characteristic of rural America, particularly as it affects the availability and access to healthcare resources and the familiarity among rural community members, have important implications for a public health response. Interventions in these settings will also need to be tailored to multiple subpopulations that may be based on race/ethnicity, age, gender, sexual orientation, or a combination of these. Furthermore, many of the persons at risk for STIs, including HIV, may have long-standing distrust of medical and government institutions due to historical and ongoing social discrimination (e.g., racism, classism, homophobia) they may have encountered in their communities [87]. Tailoring STI prevention and control services to the intervention group's unique experiences and circumstances is essential $[89,90]$.

The literature is limited regarding the intersectionality of historical trauma, stigma, and other determinants of health in STI prevention, particularly in rural communities. It is critical to explore these topics to better address such barriers. However, despite being mainly set in urban areas, there are nevertheless relevant lessons that can be shared with rural-based programs. The development of community-engaged, culturally competent, and innovative strategies involving telehealth can be shared with rural STI prevention programs. 


\section{Community Engagement}

Authentic community engagement methods have long existed to promote healthy behaviors [91], and a growing number of STI prevention and control programs are using these methods. In rural environments, typically STI prevention planning and education comes as a result of dramatic increases in new STI diagnoses in a given community [92]. A program in outbreak response mode often will not take the time to account for the historical trauma and long-standing health disparities that impact the community of interest, particularly among racial and ethnic subpopulations. Yet, Community-based participatory (CBPR) methods rapidly deployed in intervention planning, coordination, and implementation can increase the effectiveness of the outbreak response and build sustainability over time [92]. For example, researchers implemented a fluid CBPR model with informal decision-making processes towards STI/HIV prevention with a male Hispanic/Latino group with increased risk of STI/HIV transmission in a rural town in North Carolina. The study showed that these men were willing to serve as designated Lay health advisors (LHA) to design, plan, advocate, and coordinate STI/HIV prevention strategies in their community. It also showed that when the men from the community served as active decision-makers in the intervention design it reduced the impact of social barriers, including stigma, and effectively promoted sexual health [93].

Another example demonstrating the power of community engagement to reduce STIs is the federal initiative, Community-based approaches to reducing sexually transmitted diseases (CARS), that funds recipients to use community engagement methods and partnerships to build local STI prevention and control capacity [94]. CARS requires funded projects to work in tandem with targeted populations to address STI prevention services through community advisory boards and collaborative partnerships that leverage provider, community resources and expertise [95]. One CARS project based in New Mexico among the Navajo was able to use an internal Community advisory board (CAB) comprising Navajo adolescents to address the determinants health, including cultural sensitivity and stigma, impacting STI prevention and control. Through community health assessments, the $\mathrm{CAB}$ found that many of the members of their Navajo community were underserved and plagued by the barriers of enormous distances to places of livelihood (e.g., grocery stores, hospitals, health care centers) and limited transportation options. One positive outcome of the empowered Navajo community effort was the establishment of a collaboration with a local transportation service to provide free transportation between the community and STI/HIV testing facilities [95]. A communal solution such as increasing access to transportation to receive STI care, guided by the adolescents directly impacted by the problem, improved trust for future interventions, and reduced the stigma associated with accessing STI care.

\section{Cultural Values and Beliefs}

Engaging an affected group in the STI intervention effort can enhance a program's understanding of the cultural caveats within different communities, whether that be language, religion, beliefs, or values. This improved understanding is critical to designing and implementing successful interventions. Effective community engagement must be culturally competent. Public Health interventions need to honor the culture-specific attitudes and beliefs of priority groups; however, many behavioral interventions and methods are often designed for and tested by white, middle-class, urban, Americans. Such interventions are rarely adequate to meet the unique needs of minority communities coping with a myriad of negative determinants, including stigma [96], particularly in rural settings. Diversity exists within rural America too, especially with respect to race and ethnicity, and including immigration status. This diversity is reflected in the local, cultural, and social contexts of these communities.

Given the increase of non-US born immigrants and mono-linguistically Spanish speaking persons in rural U.S. communities, carefully crafted culturally-informed interventions are imperative to reduce STIs in these populations [89]. Although monolithically Spanish speaking, there are differences in important sociocultural factors among Hispanic/Latino cultures that can impact sexual behaviors and increase risk for STIs. These include, but are not limited to, sexual silence, machismo (masculine ideal of male behavior as dominant, aggressive), and marianismo (feminine ideal of female behaviors as passive, submissive) [89]. Such factors can also lead to significant experiences of stigma, whether it be enacted or felt.

The social and cultural context can affect the trust between providers and patients, potentially undermining or perhaps even enhancing the provider-patient relationship. This is crucial to STI prevention and control [97, 98]. Despite the challenges sometimes experienced in implementation, better provider training, including all patient-facing staff, on cultural sensitivity and unconscious bias can be invaluable [99]. The well-trained provider can work to reduce the impact of stigma and more effectively address other determinants that can impede health seeking behaviors of patients [100]. To tailor preventive services and treatment to individual sexual health needs requires a life-course perspective of health that accounts for a range of relative cultural circumstances. Cultural humility, defined as "a process of being aware of how people's culture can impact their health behaviors and in turn using this awareness to cultivate sensitive approaches in treating 
patients" [101] can increase the trust between patient and provider and lessen the stigma associated with STI health seeking behaviors [102].

\section{Telehealth}

A third potential way to reduce the interpersonal stigma risks associated with an individual seeking STI care is Telehealth. Increasingly, Telehealth is not only socially protective but is also simply practical. Geographic isolation results in limited healthcare services and resources [103]. Ongoing closings of rural health practices and hospitals and the loss of a rural health care workforce threaten the health of rural Americans [104]. Telehealth, or telemedicine, defined as "the use of electronic communication and information technologies to provide or support long-distance clinical care" is an effective innovative approach for providing safe and private health care access [105]. Telehealth can answer the problems of diminished availability of primary and specialty healthcare, and the lack of transportation [106]. It can increase a patient's quality of life, reduce hospital admissions, and reduce stigma, especially the stigma associated with seeking mental health care [103].

Calls for telehealth services have become more common for STI prevention, screening, and care, particularly as selfcollection testing kits and diagnostics [107] availability has increased. Continued investment in the necessary infrastructure to coordinate care is needed. For example, the advancements in telehealth services for rural farmworker communities in North Carolina, communities where access to health care services are scarce, have improved prevention education and screening for infectious diseases such as COVID-19 by decreasing barriers to access [108]. These lessons learned from the COVID-19 response are applicable to STI prevention and control. It is important to sustain such innovations to promote rural health equity.

Telehealth with its mobile applications and online services can provide STI consultation, testing, and treatment thus lessening the need for in-person clinic visits. Advancements in the field combining educational content, contact tracing, counseling, and coping skills to reduce HIV-related stigma are continuing [109]. Multiple studies already point to benefits from Short-message services (SMS), or text messaging, on sexual health promotion and STI clinical management, particularly among adolescents, in terms of cost, accessibility, and privacy. Being able to contact a health care provider without the fear of being identified by neighbors, friends, or family can alleviate the stressors associated with STI stigma [107]. More research is needed to evaluate the impact of Telehealth for providing care and reducing stigma [110].

\section{Conclusions}

Place clearly matters when it comes to health status [111]. Although it may have taken the COVID-19 pandemic to focus national attention on the challenges facing public health in rural areas, the unfortunate truth is that many rural communities have long-struggled with disparate health outcomes. STI disparities, including disparities in HIV rates, are not limited to densely populated urban cities. These epidemics plague rural communities, too.

To successfully implement STI prevention and control, adequate public health infrastructure is critical. The Sexually Transmitted Infections National Strategic Plan for The United States (2021-2025) recently released by the U.S. Department of Health and Human Services asserts the need for expansion of innovative and evidence-based models "that increase the quality and convenience of STI testing, care, and treatment such as telehealth" [112]. Yet for many rural jurisdictions this basic infrastructure is sorely lacking. Even the promising benefits of Telehealth must be tempered by the inequity of internet and broadband access in rural areas [113].

However, even if increased resources were suddenly made available, leading to increased STI prevention and control services, social stigma could leave those services underutilized. To paraphrase the famous line from the 1989 film, Field of Dreams, simply building an STI program does not ensure that the communities will come and use those services. It is critical to consider how those services are built, how they are designed and implemented. STI prevention programs for rural communities need comprehensive frameworks that address multiple determinants, structural, individual, and interpersonal. Programs will need to engage with affected communities and groups to develop, execute, and even evaluate intervention efforts. Collaborative partnerships between providers, communities, and in many cases other institutions such as schools, religious organizations, and local colleges will require authentic commitment to cultural sensitivity, as well as respect for the lived experiences of all rural citizens, especially racial/ethnic minority populations and immigrant populations. The expertise and active involvement of community members regarding decisions based on their needs, barriers, and opportunities for better health is not only an asset, but a gateway for sustainable, successful, nonstigmatizing STI prevention programs.

\section{Declarations}

Conflict of interest The authors have no conflict or competing interests regarding this paper. 
Ethical Approval This paper represents the opinions, findings, and conclusions of the authors and does not necessarily reflect the official position, views, or policies of CDC/ATSDR.

\section{References}

1. Caldwell JT, Ford CL, Wallace SP, Wang MC, Takahashi LM. Intersection of living in a rural versus urban area and race/ethnicity in explaining access to health care in the United States. Am J Public Health. 2016;106(8):1463-9.

2. Census. Place of birth by nativity and citizenship status, 2018 American Community Survey. U.S. Bureau of the Census; 2020.

3. Julien HM, Eberly LA, Adusumalli S. Telemedicine and the forgotten America. Circulation. 2020;142(4):312-4.

4. Naylor KB, Tootoo J, Yakusheva O, Shipman SA, Bynum JPW, Davis MA. Geographic variation in spatial accessibility of U.S. healthcare providers. PLoS ONE. 2019;14(4):e0215016.

5. Rogstad K. Sexually transmitted infections: controversies and conundrums in screening, treatment and stigma. Curr Opin Infect Dis. 2014;27(1):53-5.

6. USDA. Rural Classifications 2019. 2019

7. Leider JP, Meit M, McCullough JM, Resnick B, Dekker D, Alfonso YN, et al. The state of rural public health: enduring needs in a new decade. Am J Public Health. 2020;110(9):1283-90.

8. Raglan GB, Lannon SM, Jones KM, Schulkin J. Racial and ethnic disparities in preterm birth among American Indian and Alaska native women. Matern Child Health J. 2016;20(1):16-24

9. Caldwell JT, Ford CL, Wallace SP, Wang MC, Takahashi LM. Racial and ethnic residential segregation and access to health care in rural areas. Health Place. 2017;43:104-12.

10. James CV, Moonesinghe R, Wilson-Frederick SM, Hall JE, Penman-Aguilar A, Bouye K. Racial/ethnic health disparities among rural adults - United States, 2012-2015. MMWR Morb Mortal Wkly Rep. 2017;66(23):1-9.

11. Meyerson BE, Davis A, Reno H, Haderxhanaj LT, Sayegh MA, Simmons MK, et al. Existence, distribution, and characteristics of STD clinics in the United States. Public Health Rep. 2017;134(4):371-8.

12. Leichliter JS, Heyer K, Peterman TA, Habel MA, Brookmeyer KA, Arnold Pang SS, et al. US public sexually transmitted disease clinical services in an era of declining public health funding: 2013-14. Sex Trans Dis. 2017;44(8):505-9.

13. Fauci AS, Redfield RR, Sigounas G, Weahkee MD, Giroir BP. Ending the HIV epidemic: a plan for the United States. JAMA. 2019;321(9):844-5.

14. Paschal AM, Oler-Manske J, Hsiao T. The role of local health departments in providing sexually transmitted disease services and surveillance in rural communities. J Community Health. 2011;36(2):204-10.

15. Harris JK, Beatty K, Leider JP, Knudson A, Anderson BL, Meit M. The double disparity facing rural local health departments. Annu Rev Public Health. 2016;37:167-84.

16. Melvin SC, Wiggins C, Burse N, Thompson E, Monger M. The role of public health in COVID-19 emergency response efforts from a rural health perspective. Prev Chronic Dis. 2020;17:E70.

17. Beatty KE, Erwin PC, Brownson RC, Meit M, Fey J. Public health agency accreditation among rural local health departments: influencers and barriers. JPHMP. 2018;24(1):49-56.

18. Adler NE, Rehkopf DHUS. disparities in health: descriptions, causes, and mechanisms. Annu Rev Public Health. 2008;29:235-52.
19. Douthit N, Kiv S, Dwolatzky T, Biswas S. Exposing some important barriers to health care access in the rural USA. Public Health. 2015;129(6):611-20.

20. Khoong EC, Gibbert WS, Garbutt JM, Sumner W, Brownson RC. Rural, suburban, and urban differences in factors that impact physician adherence to clinical preventive service guidelines. J Rural Health. 2014;30(1):7-16.

21. Weigel PA, Ullrich F, Shane DM, Mueller KJ. Variation in primary care service patterns by rural-urban location. J Rural Health. 2016;32(2):196-203.

22. Kreisel KM, Spicknall IH, Gargano JW, Lewis FM, Lewis RM, Markowitz LE, et al. Sexually transmitted infections among US women and men: prevalence and incidence estimates, 2018. Sexually Trans Dis. 2021;48(4):208-14.

23. CDC. Sexually transmitted disease surveillance 2019. Atlanta, GA: Centers for Disease Control; 2021.

24. López de Munain J. Epidemiology and current control of sexually transmitted infections. The role of STI clinics. Enferm Infecc Microbiol Clin. 2019;37(1):45-9.

25. Workowski KA, Bolan GA. Sexually transmitted diseases treatment guidelines, 2015. MMWR Morb Mortal Wkly Rep . 2015;64(03):1-137.

26. Zahnd WE, Rodriguez C, Jenkins WD. Rural-urban differences in human papillomavirus-associated cancer trends and rates. J Rural Health. 2019;35(2):208-15.

27. Haley T, Puskar K, Terhorst L, Terry MA, Charron-Prochownik D. Condom use among sexually active rural high school adolescents personal, environmental, and behavioral predictors. J Sch Nurs. 2013;29(3):212-24.

28. Yan AF, Chiu YW, Stoesen CA, Wang MQ. STD-/HIV-related sexual risk behaviors and substance use among U.S. rural adolescents. J Natl Med Assoc. 2007;99(12):1386-94.

29. Kozhimannil KB, Enns E, Blauer-Peterson C, Farris J, Kahn J, Kulasingam S. Behavioral and community correlates of adolescent pregnancy and Chlamydia rates in rural counties in Minnesota. J Community Health. 2015;40(3):493-500.

30. Pinto CN, Dorn LD, Chinchilli VM, Du P, Chi G. Rural counties chlamydia and gonorrhea rates in Pennsylvania among adolescents and young adults. Ann Epidemiol. 2017;27(9):606-10.e2.

31. OMB. Revisions to the standards for the classification of federal data on race and ethnicity Washington, D.C.: Federal Register 1997 October 30, 1997. Contract No.: 210.

32. Chesson HW, Kent CK, Owusu-Edusei K Jr, Leichliter JS, Aral SO. Disparities in sexually transmitted disease rates across the "eight Americas." Sex Trans Dis. 2012;39(6):458-64.

33. Kahle EM, Meites E, Sineath RC, Nasrullah M, Bowles KE, DiNenno E, et al. Sexually transmitted disease testing and uptake of human papillomavirus vaccine in a large online survey of US men who have sex with men at risk for HIV infection, 2012. Sex Trans Dis. 2017;44(1):62-6.

34. Sarno EL, Bettin E, Jozsa K, Newcomb ME. Sexual health of rural and urban young male couples in the United States: differences in HIV testing, pre-exposure prophylaxis use, and condom use. AIDS Behav. 2020;25(1):191-202.

35. Rhodes SD, McCoy TP, Hergenrather KC, Vissman AT, Wolfson $\mathrm{M}$, Alonzo J, et al. Prevalence estimates of health risk behaviors of immigrant Latino men who have sex with men. J Rural Health. 2012;28(1):73-83.

36. Rosenkrantz D, Black WW, Abreu RL, Aleshire ME, FallinBennett K. Health and health care of rural sexual and gender minorities: a systemic review. Stigma Health. 2017;2:229-43.

37. Barger AC, Pearson WS, Rodriguez C, Crumly D, MuellerLuckey G, Jenkins WD. Sexually transmitted infections in the Delta regional authority: significant disparities in the 252 counties of the eight-state Delta region authority. Sex Trans Infect. 2018;94(8):611-5. 
38. Fortenberry JD, McFarlane M, Bleakley A, Bull S, Fishbein M, Grimley DM, et al. Relationships of stigma and shame to gonorrhea and HIV screening. Am J Public Health. 2002;92(3):378-81.

39. Valentine JA. Impact of attitudes and beliefs regarding African American sexual behavior on STD prevention and control in African American communities: unintended consequences. Sex Trans Dis. 2008;35(12):S23-9.

40. Rice L, Sara R. Updating the determinants of health model in the information age. Health Promot Int. 2019;34(6):1241-9.

41. Scott AJ, Wilson RF. Social determinants of health among African Americans in a rural community in the Deep South: an ecological exploration. Rural Remote Health. 2011;11(1):1634.

42. Brandt AM. Racism and research: the case of the Tuskegee syphilis study. Hastings Cent Rep. 1978;8(6):21-9.

43. Allen $\mathrm{H}$, Wright BJ, Harding K, Broffman L. The role of stigma in access to health care for the poor. Milbank Q. 2014;92(2):289-318.

44. Aral SO, O'Leary A, Baker C. Sexually transmitted infections and HIV in the southern United States: an overview. Sex Trans Dis. 2006;33(7 Suppl):S1-5.

45. USDA. Rural America at a Glance, 2018. 2018.

46. Long AS, Hanlon AL, Pellegrin KL. Socioeconomic variables explain rural disparities in US mortality rates: implications for rural health research and policy. SSM - Popul Health. 2018;6:72-4.

47. Mohamoud YA, Kirby RS, Ehrenthal DB. Poverty, urban-rural classification and term infant mortality: a population-based multilevel analysis. BMC Pregnancy Childbirth. 2019;19(1):40.

48. Hogben M, Leichliter JS. Social determinants and sexually transmitted disease disparities. Sex Trans Dis. 2008;35(12 Suppl):S13-8.

49. Biello KB, Kershaw T, Nelson R, Hogben M, Ickovics J, Niccolai L. Racial residential segregation and rates of gonorrhea in the United States, 2003-2007. Am J Public Health. 2012;102(7):1370-7.

50. Pugsley RA, Chapman DA, Kennedy MG, Liu H, Lapane KL. Residential segregation and gonorrhea rates in US metropolitan statistical areas, 2005-2009. Sex Trans Dis. 2013;40(6):439-43.

51. Bailey ZD, Krieger N, Agénor M, Graves J, Linos N, Bassett MT. Structural racism and health inequities in the USA: evidence and interventions. Lancet. 2017;389(10077):1453-63.

52. Morey BN. Mechanisms by which anti-immigrant stigma exacerbates racial/ethnic health disparities. Am J Public Health. 2018;108(4):460-3.

53. Card KG, Lachowsky NJ, Althoff KN, Schafer K, Hogg RS, Montaner JSG. A systematic review of the geospatial barriers to antiretroviral initiation, adherence and viral suppression among people living with HIV. Sex Health. 2019;16(1):1-17.

54. Logan TD, Parman JM. Segregation and mortality over time and space. Soc Sci Med. 1982;2018(199):77-86.

55. Wong MS, Steers WN, Hoggatt KJ, Ziaeian B, Washington DL. Relationship of neighborhood social determinants of health on racial/ethnic mortality disparities in US veterans-mediation and moderating effects. Health Serv Res. 2020;55(Suppl 2):851-62.

56. Smith A, Trevelyan, E. The older population in rural America: 2012-2016. American Community Survey Reports. Washington, D.C. 2018 .

57. Saint Onge JM, Smith S. Demographics in rural populations. Surg Clin N Am. 2020;100(5):823-33.

58. Winkler RL, Johnson KM. Moving toward integration? Effects of migration on ethnoracial segregation across the rural-urban continuum. Demography. 2016;53(4):1027-49.

59. Cromartie J VD. Rural population trends. In: Service UER, editor. Amber Waves Magazine 2019.

60. Rhodes SD, Hergenrather KC, Bloom FR, Leichliter JS, Montaño J. Outcomes from a community-based, participatory lay health adviser HIV/STD prevention intervention for recently arrived immigrant Latino men in rural North Carolina. AIDS Educ Prev. 2009;21(5 Suppl):103-8.

61. Dyal JW, Grant MP, Broadwater K, Bjork A, Waltenburg MA, Gibbins JD, et al. COVID-19 among workers in meat and poultry processing facilities - 19 states, April 2020. MMWR Morb Mortal Wkly Rep. 2020. https://doi.org/10.15585/mmwr. mm6918e3.

62. Shavers VL, Fagan P, Jones D, Klein WMP, Boyington J, Moten $\mathrm{C}$, et al. The state of research on racial/ethnic discrimination in the receipt of health care. Am J Public Health. 2012;102(5):953-66.

63. Sangaramoorthy T, Kroeger K. Mobility, Latino migrants, and the geography of sex work: using ethnography in public health assessments. Hum Organ. 2013;72(3):263-72.

64. Sheehan DM, Trepka MJ, Fennie KP, Prado G, Madhivanan $\mathrm{P}$, Dillon FR, et al. Individual and neighborhood determinants of late HIV diagnosis among Latinos, Florida, 2007-2011. J Immigr Minor Health. 2017;19(4):825-34.

65. Oakley LP, López-Cevallos DF, Harvey SM. The association of cultural and structural factors with perceived medical mistrust among young adult Latinos in rural Oregon. Behav Med (Washington, DC). 2019;45(2):118-27.

66. López-Cevallos DF, Harvey SM. Foreign-born Latinos living in rural areas are more likely to experience health care discrimination: results from Proyecto de Salud para Latinos. J Immigr Minor Health. 2016;18(4):928-34.

67. Walker RJ, Strom Williams J, Egede LE. Influence of race, ethnicity and social determinants of health on diabetes outcomes. Am J Med Sci. 2016;351(4):366-73.

68. Bolin JN, Bellamy GR, Ferdinand AO, Vuong AM, Kash BA, Schulze A, et al. Rural healthy people 2020: new decade, same challenges. J Rural Health. 2015;31(3):326-33.

69. Key substance use and mental health indicators in the United States: results from the 2017 National Survey on Drug Use and Health (NSDUH). Rockville, MD Substance Abuse and Mental Health Services Administration (SAMHSA), HHS/SAMHSA; 2018. Contract No.: HHS Publication No. SMA 18-5068.

70. Havens JR, Walsh SL, Korthuis PT, Fiellin DA. Implementing treatment of opioid-use disorder in rural settings: a focus on HIV and hepatitis $\mathrm{C}$ prevention and treatment. Curr HIV/AIDS Rep. 2018;15(4):315-23.

71. Van Handel MM, Rose CE, Hallisey EJ, Kolling JL, Zibbell JE, Lewis B, et al. County-level vulnerability assessment for rapid dissemination of HIV or HCV infections among persons who inject drugs, United States. J Acquir Immune Defic Syndr. 2016;73(3):323-31.

72. Broz D, Zibbell J, Foote C, Roseberry JC, Patel MR, Conrad C, et al. Multiple injections per injection episode: high-risk injection practice among people who injected pills during the 2015 HIV outbreak in Indiana. Int J Drug Policy. 2018;52:97-101.

73. Kolak MA, Chen YT, Joyce S, Ellis K, Defever K, McLuckie $\mathrm{C}$, et al. Rural risk environments, opioid-related overdose, and infectious diseases: a multidimensional, spatial perspective. Int J Drug Policy. 2020;85:102727.

74. Linn BK, Ely GE, Staton M. Latent profiles of health and reproductive risk and protective factors among women in Appalachia. J Soc Work Pract Addict. 2020;20(2):155-67.

75. Cafferky BMMM, Anderson JR, Stith SM. Substance use and intimate partner violence: a meta-analytic review. Psychol Violence. 2018;8:110-31.

76. Oesterle S, Kuklinski MR, Hawkins JD, Skinner ML, Guttmannova K, Rhew IC. Long-term effects of the communities that care trial on substance use, antisocial behavior, and violence through age 21 years. Am J Public Health. 2018;108(5):659-65. 
77. Peterson CE, Silva A, Holt HK, Balanean A, Goben AH, Dykens JA. Barriers and facilitators to HPV vaccine uptake among US rural populations: a scoping review. Cancer Causes Control. 2020;31(9):801-14.

78. Lichtenstein B, Hook EW, Sharma AK. Public tolerance, private pain: stigma and sexually transmitted infections in the American deep south. Cult Health Sex. 2005;7(1):43-57.

79. Glover JJ. Rural health care and an ethics of familiarity. Narrat Inq Bioeth. 2019;9(2):113-9.

80. Farmer GW, Blosnich JR, Jabson JM, Matthews DD. Gay acres: sexual orientation differences in health indicators among rural and nonrural individuals. J Rural Health. 2016;32(3):321-31.

81. Zinik G. Identity conflict or adaptive flexibility? Bisexuality reconsidered. J Homosex. 1985;11(1-2):7-19.

82. Adimora AA, Schoenbach VJ, Doherty IA. HIV and African Americans in the southern United States: sexual networks and social context. Sex Trans Dis. 2006;33(7 Suppl):S39-45.

83. Schafer KR, Albrecht H, Dillingham R, Hogg RS, Jaworsky D, Kasper K, et al. The continuum of HIV care in rural communities in the united states and Canada: what is known and future research directions. J Acquir Immune Defic Syndr. 2017;75(1):35-44.

84. Contesse MG, Fredericksen RJ, Wohlfeiler D, Hecht J, Kachur R, Strona FV, et al. Attitudes about the use of geosocial networking applications for HIV/STD partner notification: a qualitative study. AIDS Educ Prev. 2019;31(3):273-85.

85. Hubach RD, O'Neil AM, Stowe M, Hamrick J, Giano Z, Currin JM. Preferred methods of HIV and sexually transmissible infection screening delivery among a rural sample of men who have sex with men. AIDS Patient Care STDS. 2020;34(11):470-6.

86. Smedley B, Stith, AY, Nelson, AR, editor. Unequal treatment: confronting racial and ethnic disparities in healthcare Washington, DC Institute of Medicine National Academy Press; 2002.

87. Foster PH. Use of stigma, fear, and denial in development of a framework for prevention of HIV/AIDS in rural African American communities. Fam Community Health. 2007;30(4):318-27.

88. Sexually transmitted infections: adopting a sexual health paradigm Washington, D.C.: National Academies of Sciences, Engineering, and Medicine 2021.

89. Villar-Loubet OM, Vamos S, Jones DL, Lopez E, Weiss SM. A cultural perspective on sexual health: HIV positive and negative monolingual Hispanic women in South Florida. Hispanic Health Care Int. 2011;9(2):82-90.

90. Cristancho S, Peters K, Garces M. Health information preferences among Hispanic/Latino immigrants in the U.S. rural Midwest. Glob Health Promot. 2014;21(1):40-9.

91. Piper K, Enah C, Daniel M. Black southern rural adolescents' HIV stigma, denial, and misconceptions and implications for HIV prevention. J Psychosoc Nurs Ment Health Serv. 2014;52(6):50-6.

92. Gesink Law D, Rink E, Mulvad G, Koch A. Sexual health and sexually transmitted infections in the North American Arctic. Emerg Infect Dis. 2008;14(1):4-9.

93. Daniel-Ulloa J, Sun C, Rhodes SD. The intersection between masculinity and health among rural immigrant Latino men. Int J Men Health. 2017;16(1):84-95.

94. Rhodes SD, Daniel-Ulloa J, Wright SS, Mann-Jackson L, Johnson DB, Hayes NA, et al. Critical elements of community engagement to address disparities and related social determinants of health: the centers of disease control and prevention community approaches to reducing sexually transmitted disease initiative. Sex Trans Dis. 2021;48(1):49-55.

95. Delgado L, Wright S. Unpublished CARS year 3 final interview. Community approaches to reducing sexually transmitted diseases (CARS) 2020.

96. Barrow RY, Berkel C, Brooks LC, Groseclose SL, Johnson DB, Valentine JA. Traditional sexually transmitted disease prevention and control strategies: tailoring for African American communities. Sex Trans Dis. 2008;35(12 Suppl):S30-9.

97. Thomas JC. From slavery to incarceration: social forces affecting the epidemiology of sexually transmitted diseases in the rural South. Sex Trans Dis. 2006;33(7 Suppl):S6-10.

98. Brach C, Fraser I. Can cultural competency reduce racial and ethnic health disparities? A review and conceptual model. Med Care Res Rev. 2000;57(Suppl 1):181-217.

99. Butler M, McCreedy E, Schwer N, Burgess D, Call K, Przedworski J, et al. AHRQ comparative effectiveness reviews. Improving cultural competence to reduce health disparities. Rockville (MD): Agency for Healthcare Research and Quality (US); 2016.

100. Ford JV, Barnes R, Rompalo A, Hook EW. Sexual health training and education in the U.S. Public Health Rep. 2013;128(Suppl 1):96-101.

101. Prasad SJ, Nair P, Gadhvi K, Barai I, Danish HS, Philip AB. Cultural humility: treating the patient, not the illness. Med Educ Online. 2016;21:30908.

102. Van Wagoner NJ, Harbison HS, Drewry J, Turnipseed E, Hook EW 3rd. Characteristics of women reporting multiple recent sex partners presenting to a sexually transmitted disease clinic for care. Sex Trans Dis. 2011;38(3):210-5.

103. Marhefka SL, Lockhart E, Turner D, Wang W, Dolcini MM, Baldwin JA, et al. Social determinants of potential eHealth engagement among people living with HIV receiving Ryan white case management: health equity implications from project TECH. AIDS Behav. 2020;24(5):1463-75.

104. Mishori R, Antono B. Telehealth, rural America, and the digital divide. J Ambul Care Manag. 2020;43(4):319-22.

105. HRSA. Telehealth - HRSA: Rural Health Glossary 2015.

106. Nitzinger V, Held S, Kevane B, Eudave Y. Latino Health Perceptions in rural Montana: engaging promotores de Salud using photovoice through Facebook. Fam Community Health. 2019;42(2):150-60.

107. Weigel G, Frederiksen B, Ranji U, Salganicoff A. Telemedicine in sexual and reproductive health; 2019. Available from https://www. kff.org/womens-health-policy/issue-brief/telemedicine-in-sexualand-reproductive-health/.

108. NC Farmworker Health Program Raleigh, North Carolina Office of Rural Health; 2021. Available from https://www.ncfhp.org/.

109. Rao D, Frey S, Ramaiya M. eHealth for stigma reduction efforts designed to improve engagement in care for people living with HIV. Curr HIV/AIDS Rep. 2018;15(6):397-402.

110. Lim MS, Hocking JS, Hellard ME, Aitken CK. SMS STI: a review of the uses of mobile phone text messaging in sexual health. Int $\mathrm{J}$ STD AIDS. 2008;19(5):287-90.

111. Yang TC, Park K, Matthews SA. Racial/ethnic segregation and health disparities: future directions and opportunities. Sociol Compass. 2020. https://doi.org/10.1111/soc4.12794.

112. HHS. Sexually transmitted infections national strategic plan for the United States Washington, D.C.: U.S. Department of Health and Human Services; 2020. Available from https://www.hhs.gov/ programs/topic-sites/sexually-transmitted-infections/plan-overv iew/index.html\#: :text=\%20The\%20STI\%20Plan\%20has\%20five\% 20high-level $\% 20$ goals $\% 3 \mathrm{~A}$,efforts $\% 20$ that $\% 20$ address $\% 20$ the $\%$ 20STI\%20epidemic.\%20More\%20.

113. Drake C, Zhang Y, Chaiyachati KH, Polsky D. The limitations of poor broadband internet access for telemedicine use in rural America: an observational study. Ann Intern Med. 2019;171(5):382-4.

Publisher's Note Springer Nature remains neutral with regard to jurisdictional claims in published maps and institutional affiliations. 